\title{
Behavioral modulation by mutilation pictures in women
}

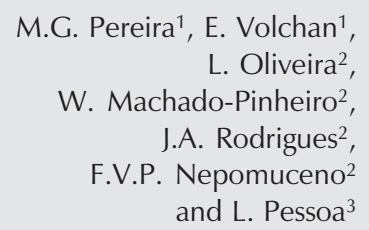

\author{
1Departamento de Neurobiologia, Instituto de Biofísica, \\ Universidade Federal do Rio de Janeiro, Rio de Janeiro, RJ, Brasil \\ ${ }^{2}$ Departamento de Fisiologia e Farmacologia, Universidade Federal Fluminense, \\ Niterói, RJ, Brasil \\ ${ }^{3}$ National Institute of Mental Health, Bethesda, MD, USA
}

\section{Correspondence}

M.G. Pereira

Departamento de Neurobiologia

Instituto de Biofísica, UFRJ

CCS, Bloco G

21949-900 Rio de Janeiro, RJ

Brasil

Fax: +55-21-2280-8193

E-mail: mfortes@biof.ufrj.br

Research supported by PRONEX/MCT, CNPq and FAPERJ.

Received March 14, 2003 Accepted November 10, 2003

\begin{abstract}
Previous studies have shown that women are more emotionally expressive than men. It is unclear, however, if women are also more susceptible to the emotional modulation of behavior imposed by an affective stimulus. To investigate this issue, we devised a task in which female subjects performed six sequential trials of visual target detection following the presentation of emotional (mutilation and erotic) or neutral pictures (domestic utensils and objects) and compared the data obtained in the present study with those described in a previous study with male subjects. The experiment consisted of three blocks of 24 pictures and each block had an approximate duration of $4 \mathrm{~min}$. Our sample consisted of 36 subjects (age range: 18 to 26 years) and each subject performed all blocks. Trials following the presentation of mutilation pictures $(283 \mathrm{~ms})$ had significantly slower reaction times than those following neutral $(270 \mathrm{~ms})$ pictures. None of the trials in the "pleasant block" (271 ms) was significantly different from those in the "neutral block". The increase in reaction time observed in the unpleasant block may be related in part to the activation of motivational systems leading to an avoidance behavior. The interference effect observed in this study was similar to the pattern previously described for men. Thus, although women may be more emotionally expressive, they were not more reactive to aversive stimuli than men, as measured by emotional interference in a simple reaction time task.
\end{abstract}

\section{Introduction}

The fast, effortless processing of potentially threatening stimuli is highly advantageous and may be critical for survival. Several researchers have proposed that the processing of a negative stimulus may be "automatic" $(1,2)$. Psychophysical studies have shown that observers exhibit fast, involuntary responses to emotional stimuli, such as faces with fearful expressions or aversive
Key words

- Emotion

- Behavior

- Reaction time

- Sex differences

- Affective stimulus

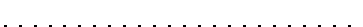

pictures (3-5) . However, many studies suggest that there are sex differences in the responses to emotional stimuli. Conventional wisdom (at least in some cultures) suggests that women are more "emotional" than men (6). Does this mean that women express, experience or have stronger physiological responses than men? In fact, a substantial body of research has demonstrated that women are more emotionally expressive than men (for a review, see Ref. 7). However, 
Kring and Gordon (8) stated that women do not report experiencing more emotion than men and their skin conductance activity is different but not directly consistent with the view that women are more emotional. According to those investigators, differences between men and women in the physiological response, at least for skin conductance activity, varied according to type of emotion, particularly for negative emotions. In these experiments, men showed greater reactivity to fear and anger films, and women had greater reactivity to sad and disgusting films.

Other studies suggest that women are more reactive to unpleasant events, especially those that are threatening or traumatic (9). Bradley et al. (10) investigated sex differences in emotional picture processing and obtained results consistent with the idea that women are more reactive to aversive stimulation. In their study, they compared the responses of men and women to pleasant and unpleasant pictures (of varied contents) and demonstrated that women were more reactive to unpleasant materials, rating the pictures as more arousing and more unpleasant, and also reacted with more marked changes in electromyographic recordings of corrugator activity. Women also responded with greater fear bradycardia (cardiac deceleration) when viewing unpleasant pictures. According to the investigators, these data suggest that symbolic picture cues activate the defensive motivational system more intensely in women than in men. In contrast, men tended to be marginally more reactive than women when viewing pleasant pictures, rating these pictures slightly more pleasant and more arousing, and reacting with more skin conductance activity (10).

In addition to the wide range of direct emotional responses evoked by affective pictures $(3,11)$ the processing of emotional stimuli by human subjects can also interfere with the performance of non-emotional attentional tasks $(12,13)$. On the basis of the statement made by Bradley et al. $(14,15)$ that, among others, erotic and attack-mutilation pictures most strongly activate the primary motivational states (i.e., appetitive and defensive states, respectively), we tested the effects of viewing these categories of pleasant and unpleasant pictures in a subsequent simple detection task in a male sample. In this study (16) we demonstrated that emotional pictures induced a sustained interference with a simple detection task. Subjects performed six sequential trials of simple target detection following the offset of each picture. Reaction times for trials presented after mutilation pictures were significantly slower than those presented after erotic or neutral pictures. As discussed above, many studies have measured direct physiological or evaluative responses evoked by affective stimuli and have suggested that women appear to be more emotionally expressive than men, and there is also some evidence for their hyperreactivity to aversive pictures. Would this mean that women are more susceptible to the emotional modulation of behavior imposed by affective stimuli (at least highly arousing stimuli)?

To investigate this issue, we repeated the same paradigm as used in our previous study, but now applied to a group of women. By comparing the data obtained in the present study to the results described previously for men, we can assess if emotional modulation of a behavioral task has a similar pattern for both sexes. Evaluative judgments were also performed in order to check for sex differences in rating reports (10) in our sample.

\section{Subjects and Methods}

\section{Subjects}

Thirty-six female volunteers participated in the experiment (age range: 18-26 years). Subjects were college students from the Federal Fluminense University, Rio de Janeiro, RJ, Brazil, who reported no neurological or 
psychiatric disorders, and none were taking medication. All of them were right-handed according to the Edinburgh Inventory (17) and had normal or corrected vision. The local Ethics Committee approved the experimental protocol and each subject gave written informed consent to participated in the study.

\section{Apparatus and stimulus selection}

Subjects were tested in a sound-attenuated room under dim ambient light. Stimulus timing and presentation, as well as collection of responses, were controlled by a computer. Stimulus presentation was programmed using MEL software (Psychology Software Tools Inc., Pittsburgh, PA, USA). The subjects' head was positioned on a headand-chin rest $57 \mathrm{~cm}$ from the screen.

Ninety pictures were used in the whole experiment. Seventy-nine were selected from the International Affective Picture System, a collection of standardized color photographic material $(18,19)$. Eleven additional erotic male pictures were obtained on the Internet. We divided these pictures into four sets. Three sets of 24 pictures each were used in test blocks: pleasant (erotic males or erotic couples), neutral (household and inanimate objects) and unpleasant (mutilated bodies). One set of 18 pictures with wide-ranging valence and arousal ratings was selected for a practice block (see below).

\section{Design and procedure}

The experimental session consisted of an initial practice block followed by three test blocks. During each test block, 24 pictures of a single type were used (erotic, neutral, or mutilation). The serial position of each test block was counterbalanced across participants using all six possible orders. Pictures were presented in a fixed order within a block for all participants. We carefully aligned the pictures in a manner as unbiased as possible according to the valence and arousal ratings (18).

For all blocks, each picture was presented for $2 \mathrm{~s}$, followed by six trials of target detection. Subjects were instructed to attend to the picture as long as it was displayed. After picture offset, a fixation spot was presented in the center of the screen for 500 to $700 \mathrm{~ms}$ and then the target (a small annulus) appeared around it (see Figure 1). Both the fixation spot and the target were presented in white on a black screen and remained on until the subject's response. Subjects were required to press a button with the right index finger as soon as they detected the target. The next trial began $500 \mathrm{~ms}$ after the subject's response, with the onset of the fixation spot. After six trials, a new picture appeared on the screen. Trials with responses longer than $1000 \mathrm{~ms}$ or shorter than $100 \mathrm{~ms}$

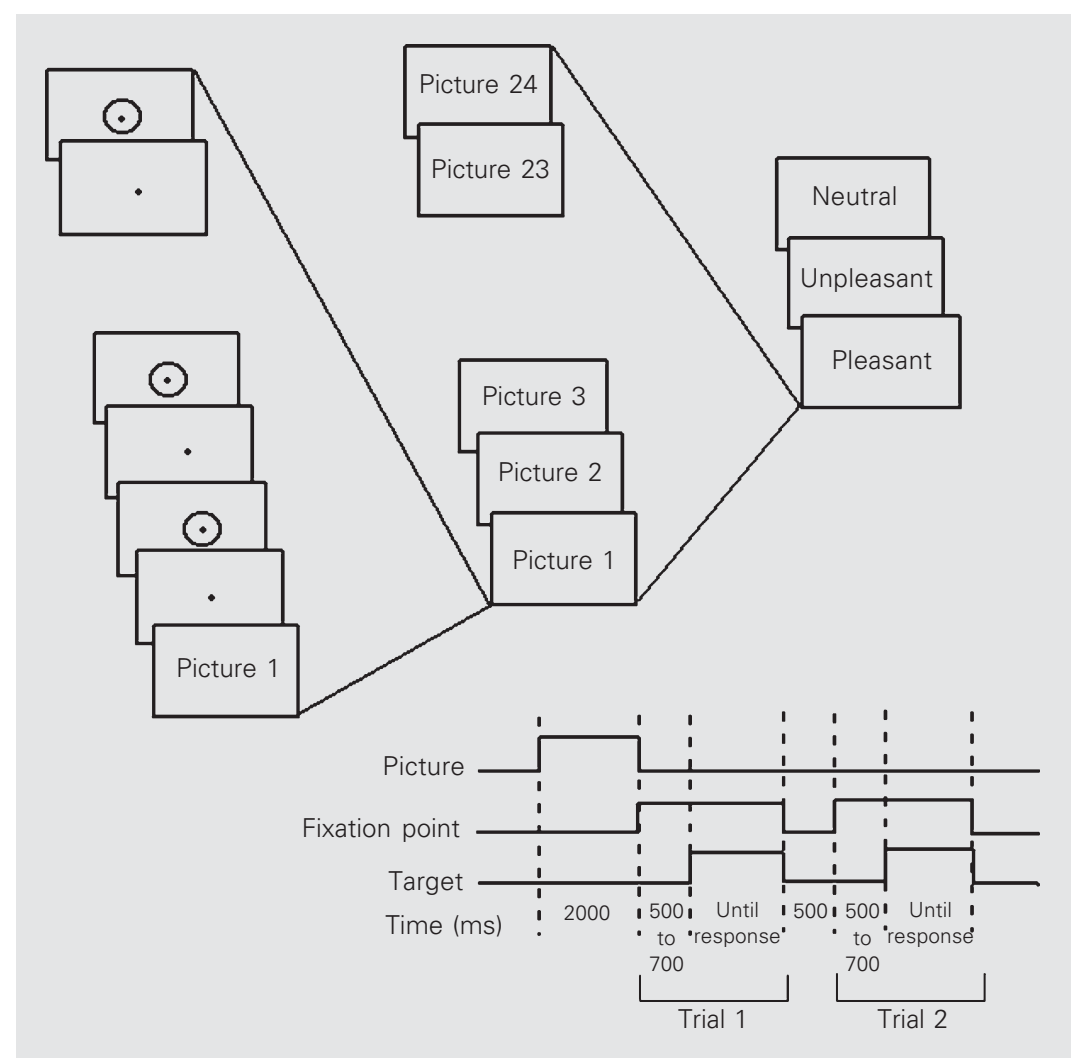

Figure 1. Schematic representation of the experimental design. Neutral, unpleasant, and pleasant blocks consisted of 24 pictures. Each picture was followed by six trials of a simple target detection task. The lower part of the figure presents the temporal structure associated with each picture and subsequent detection trials. 
were considered errors and were discarded (less than $5 \%$ of the trials).

The choice for a blocked presentation of pictures was based on the study by Bradley et al. (20), who reported that emotional modulation in the interpicture interval is only elicited under a blocked paradigm.

During the practice block a visual feedback of the response latency (in milliseconds) appeared on the screen for $1 \mathrm{~s}$. After the offset of the display with reaction time, a new trial began. Errors were displayed on the screen as "anticipation" or "slow response", also for $1 \mathrm{~s}$. There was no visual feedback of the response latency in test blocks.

\section{Statistical analysis}

Data from two subjects who had a mean reaction time slower than the group average

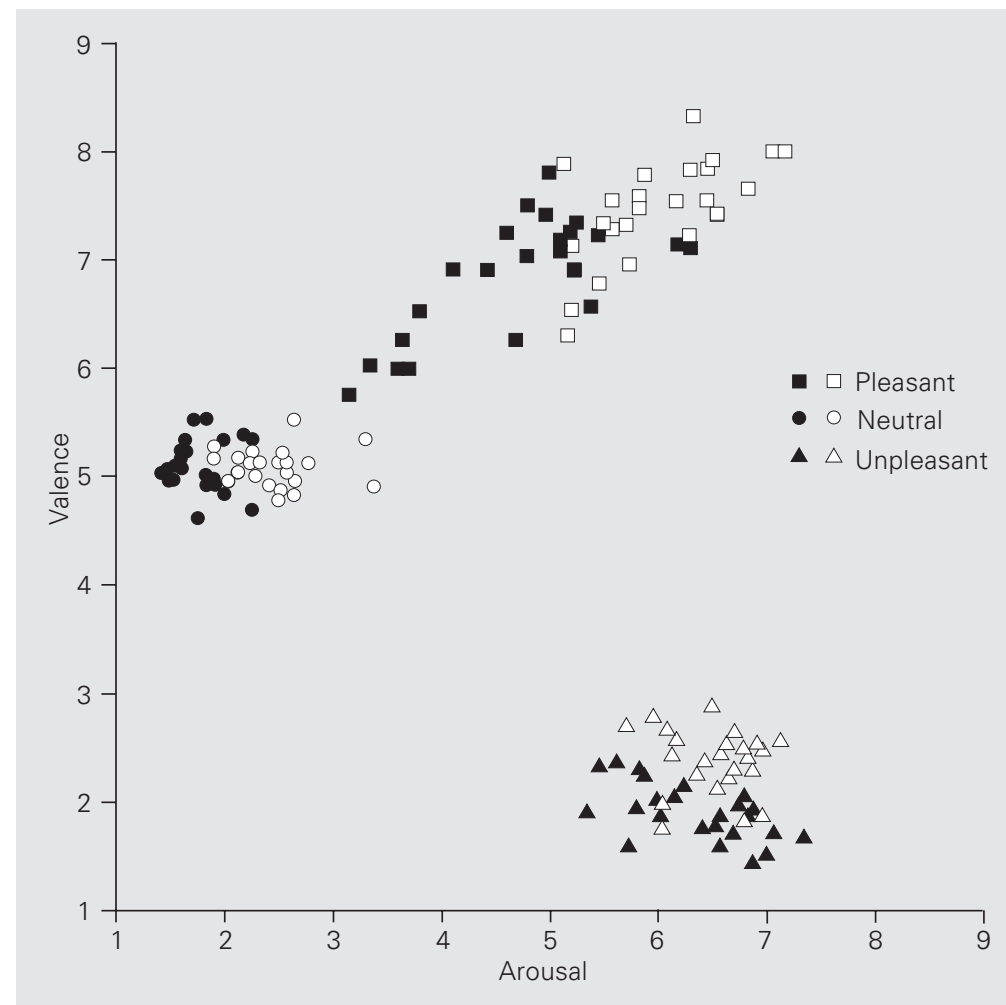

Figure 2. Ratings of women (closed symbols) and men (open symbols). Each symbol depicts the mean valence and arousal ratings for pleasant, unpleasant and neutral pictures. The data for women are from the present study and the data for men were taken from a previous study (16). minus 3 standard deviations were not included in the analysis of the test blocks. The mean reaction time for each block was submitted to a repeated-measures ANOVA test. Valence (pleasant, neutral or unpleasant) and trial number (1-6) were used as withinsubject factors. Post hoc tests were carried out by the Newman-Keuls method. The level of significance adopted was $\mathrm{P}<0.05$.

\section{Rating session}

After the end of the behavior experimental session, an evaluative report of the previously presented pictures began. The pictures used in the rating session were presented in three sets of 30 pictures each. They were the same 90 pictures as described before, but randomly distributed. The rating session began with a preparation slide ("Get ready to rate the next image"), which was presented for $5 \mathrm{~s}$. Then images were presented for $6 \mathrm{~s}$. During the 10-s interval between pictures, participants were asked to rate the picture (in a ratings booklet) on the dimensions of valence and arousal using the paper and pencil version of the self-assessment manikin, an affective rating system devised by Lang et al. $(18,21)$. In this system, ratings of valence are indicated by 5 graphic representations of facial expressions ranging from a severe frown (most negative) to a broad smile (most positive). For arousal, the manikin varies from a state of low to high agitation. Participants may select any of the five figures comprising each scale, or the boxes between any two figures, which results in a nine point rating scale for each dimension. In the valence dimension, 9 represents the extreme of pleasantness and 1 the extreme of unpleasantness. For the arousal dimension, ratings are such that 9 represents a high rating and 1 represents a low rating. Before the rating of the pictures, 9 pictures were used in order to demonstrate the rating scales. Additionally, subjects practiced their ratings on 3 practice pictures. 


\section{Results}

Valence ratings of erotic $($ mean $=6.9)$ pictures were significantly higher and valence ratings of mutilation pictures (mean = 1.9) were significantly lower than valence ratings of neutral pictures (mean $=5.1$ ). Arousal ratings were greater for pleasant $($ mean $=4.7)$ and mutilation $($ mean $=6.3)$ pictures than for neutral ones (mean $=1.8$ ); mutilation and erotic pictures differed significantly in arousal level (see in Figure 2). As proposed by Bradley et al. (10), by computing the correlation between pleasure and arousal ratings it is possible to determine the "vectors" that describe appetitive and defensive motivation. To assess these motivation vectors, we computed the correlation between pleasure and arousal ratings for each group of pictures separately. There was a significant correlation between ratings of pleasure and arousal for erotic $(\mathrm{r}=0.73, \mathrm{P}<$ $0.001)$ and mutilation $(r=-0.60, P=0.002)$ pictures, but no correlation was found for neutral pictures $(\mathrm{r}=0.02, \mathrm{P}=0.92)$.

The analysis of reaction times revealed a main effect of valence $(\mathrm{F}[2,66]=4.06, \mathrm{P}=$ $0.02)$. Mean reaction times to targets were significantly slower following mutilation pictures $(283 \mathrm{~ms})$ than those following neutral pictures $(270 \mathrm{~ms})$ and erotic pictures (271 $\mathrm{ms})$. There was no significant difference in reaction time between erotic and neutral blocks ( $\mathrm{P}=0.93)$.

There was also a main effect of trial number $(\mathrm{F}[5,165]=3.5, \mathrm{P}=0.004)$, with a faster reaction time for the second trial (262 $\mathrm{ms}$ ) following picture offset compared to all other trials $(\mathrm{P}<0.05)$, except for trial 3 (271 $\mathrm{ms}$ ), for which only a trend was observed ( $\mathrm{P}$ $=0.08)$. Post hoc analyses revealed that the second, third, fifth and sixth trials during unpleasant blocks were significantly slower than those during neutral blocks. This sustained effect is illustrated in Figure 3A. During erotic blocks, none of the trials were significantly different from those during neu- tral blocks (Figure 3B).

\section{Discussion}

Evaluative judgments confirmed that the affective pictures used in this experiment were associated with reports of pleasure or displeasure. Moreover, there was a correlation between pleasure and arousal ratings indicating that as pictures were rated as increasingly more pleasant or more unpleas-
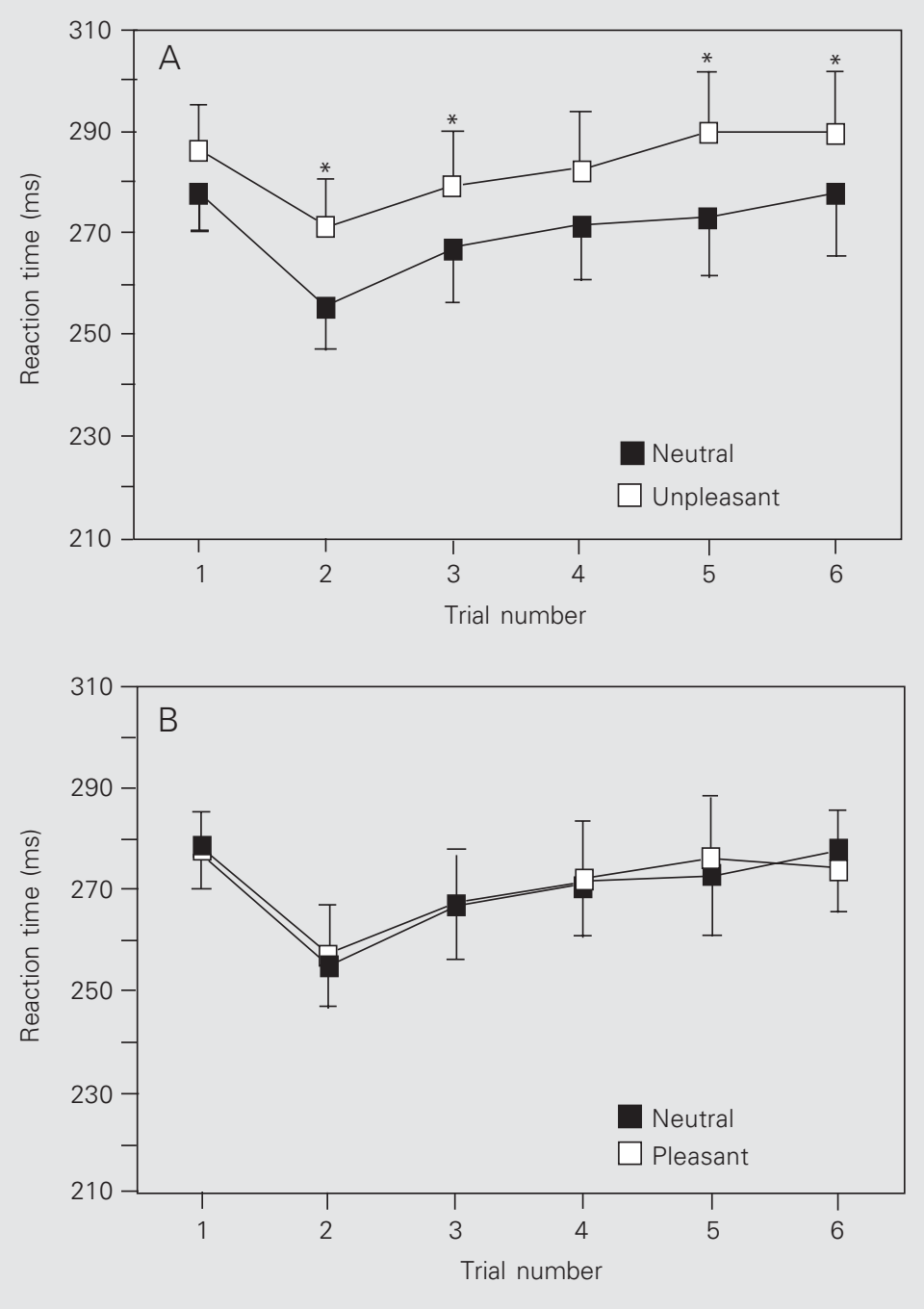

Figure 3. Sustained interference effect. Data are reported as means \pm SEM. A, A significant slowing down of manual reaction time following unpleasant pictures compared to neutral pictures was observed for trials $2,3,5$ and 6 . $B$, None of the trials involving pleasant blocks differed significantly from those involving neutral blocks. 
ant, arousal ratings tended to increase as well. We compared the ratings of the female group with the men's ratings obtained in our previous study (16) to determine if there were significant differences in evaluative judgments between groups. The pictures used in the previous study were the same, except for the pleasant pictures that were erotic photos of females instead of males. Table 1 presents the mean ratings of pleasure and arousal for women (present study) and men (16) when viewing erotic, neutral and mutilation pictures. Values reported by Lang et al. (18) for North Americans are presented in Table 2. The Brazilians' ratings for each of the 72 pictures used in the test blocks are presented in Figure 2 separately for men and women. Women rated negative pictures as significantly more unpleasant than men and positive pictures as significantly less pleasant than men. There was no difference between groups in valence ratings for neutral pictures. Men's arousal ratings for erotic and neutral pictures were significantly higher than for women. In our samples women did not find the mutilation pictures more arousing than men which is different from data reported by Bradley et al. (10) and Lang et al. (18). A comparison between the vectors describing appetitive and defensive motivation revealed that women showed a stronger coupling between increased arousal and unpleasantness $(r=-0.6 v s \mathrm{r}=-0.13$ for women and men, respectively; $\mathrm{P}=0.04$ ). Previous studies also described stronger linear defense motivation vectors for women than for men when subjects rated pictures (10), sounds or words $(22,23)$. On the other hand, these

Table 1. Ratings of valence and arousal when viewing pleasant, neutral and unpleasant pictures for women and men.

\begin{tabular}{|c|c|c|c|c|c|c|}
\hline & \multicolumn{3}{|c|}{ Valence } & \multicolumn{3}{|c|}{ Arousal } \\
\hline & Women & Men & Significance & Women & Men & Significance \\
\hline Erotic nudes & $6.9 \pm 0.5$ & $7.5 \pm 0.5$ & $P=0.0002$ & $4.7 \pm 0.8$ & $6.0 \pm 0.6$ & $P<0.0001$ \\
\hline Objects & $5.1 \pm 0.2$ & $5.1 \pm 0.2$ & $P=0.9055$ & $1.8 \pm 0.2$ & $2.4 \pm 0.4$ & $P<0.0001$ \\
\hline Mutilated bodies & $1.9 \pm 0.2$ & $2.4 \pm 0.3$ & $P<0.0001$ & $6.3 \pm 0.5$ & $6.5 \pm 0.4$ & $P=0.2248$ \\
\hline
\end{tabular}

Data are reported as mean $\pm \mathrm{SD}$. The statistical test used to compare men to women was the $t$-test. The data for females $(N=36)$ are from the present study and the data for males $(N=24)$ were taken from a previous study (16)

Table 2. International Affective Picture System (IAPS) ratings of valence and arousal for women and men when viewing pleasant, neutral and unpleasant pictures.

\begin{tabular}{lcccccccc}
\hline & \multicolumn{3}{c}{ Valence } & & \multicolumn{3}{c}{ Arousal } \\
\cline { 2 - 3 } & Women & Men & Significance & & Women & & Men & Significance \\
\hline Erotic nudes & $6.5 \pm 0.5$ & $7.5 \pm 0.5$ & $P<0.0001$ & & $5.9 \pm 0.4$ & $6.8 \pm 0.5$ & $P<0.0001$ \\
Objects & $5.0 \pm 0.3$ & $4.8 \pm 0.2$ & $P=0.0793$ & & $2.6 \pm 0.4$ & $2.4 \pm 0.4$ & $P=0.0529$ \\
Mutilated bodies & $1.5 \pm 0.3$ & $2.1 \pm 0.4$ & $P<0.0001$ & & $6.9 \pm 0.7$ & $6.1 \pm 0.6$ & $P<0.0001$
\end{tabular}

Data are reported as mean $\pm S D$. The statistical test used to compare men to women was the $t$-test. The data for both females and males were taken from IAPS (18). The ratings for the 13 erotic pictures were selected from IAPS (19). 
studies described a stronger linear appetitive motivation vector for men than for women. We did not observe any difference in linear approach vector between women and men $(\mathrm{r}$ $=0.73$ and $\mathrm{r}=0.64$, respectively; $\mathrm{P}=0.54$ ).

The data obtained in the behavioral session showed that the valence of task-unrelated pictures affects the performance of a subsequent non-emotional reaction time task in women. More specifically, responses following mutilation pictures were slower than those following neutral or erotic pictures, and there was no difference in reaction time between pleasant and neutral blocks. This slowing down of reaction time during the unpleasant block was not a transient effect of brief duration, but rather it persisted for at least $6 \mathrm{~s}$ after picture offset. This sustained effect may be linked to the blocked presentation mode of the experiment. There was no significant linear trend for an increase or a decrease of the reaction time slowing down effect across the block.

The interference effect observed in the present study is similar to the pattern reported for men by Pereira et al. (16). The difference in mean reaction time during unpleasant blocks compared to neutral blocks was virtually identical for both sexes, i.e., $13.7 \mathrm{~ms}$ for men and $12.6 \mathrm{~ms}$ for women. These data do not provide evidence of greater emotional modulation on task performance in women compared to men. Although being more emotionally expressive than men (see Ref. 7), women showed equal emotional interference with behavior, as measured by emotional influence on reaction time to ongoing tasks. Bradley et al. (10) suggest that symbolic picture cues activate the defensive motivational system more intensely in women than in men and that they are more reactive to aversive stimulation. At least for an indirect measurement of emotional influence, as used in this study, we found no support for a greater reactivity to aversive stimuli in women. One possibility is that women and men differ only in the expression of emotion, but the responses and influences of emotional stimulation are the same in both sexes. In fact, Gross and John (24) pointed out that men mask their feelings more than do women, which suggests an expressive difference, and not necessarily an experiential difference, between men and women.

A possible explanation for the present interference effect of mutilation pictures is that they are more attentionally demanding, thereby reducing available resources for the subsequent target detection task. The capacity for emotional stimuli to engage attention has been well documented (20). Selective attention effects are, in general, very fast and transient (25), with attentional dwelling time of the order of $600-800 \mathrm{~ms}$ (26). In our task, the slowing down of reaction time during the unpleasant block was observed until the sixth trial (not less than $6 \mathrm{~s}$ ). The long duration of this effect does not favor explanations solely in terms of typical selective attention effects, which, as observed above, occur within less than a second. Therefore, it is likely that other processes are involved.

Bradley et al. (15) have recently used a blocked paradigm for specific emotional categories in an investigation of visual cortex reactivity. The aim of their study was to determine if emotional stimuli that strongly engage the motivational primary states were responsible for the large activation of the visual cortex seen in previous studies with mixed categories $(27,28)$. Their choice of testing separate blocks of erotic, attack and mutilation pictures as representative of scenes expected to induce heavy engagement of the appetitive and defensive systems did result in the highest activation of the visual cortex. In a recent paper, Codispoti et al. (29) used exactly the same blocked paradigm as in the present study, i.e., mutilation as unpleasant, objects and utensils as neutral, and erotic pictures as pleasant to reveal neuroendocrine changes related to primary motivational stimuli. Concerning the pictures of mutilated bodies, Marks (30) had already 
demonstrated that evidence of death, mutilation and blood from a conspecific member is an important fear-evoking stimulus. Indeed, in 1946 Hebb (31) had observed that primates react with avoidance to signs of death or mutilation of a species member. Stevens and Gerzov-Thomas (32) working with rats, observed strong fright reactions to conspecific blood and muscle and not to tissues from another rodent species. Bradley et al. (14) also showed that humans present marked psychophysiological reactions to mutilation pictures. Additionally, work from our laboratory recording body oscillations with a force platform (33) showed that the visualization of a block of mutilation pictures decreased the postural sway and caused a marked bradycardia, revealing a defensive reactivity.

Thus, an alternative explanation for the long-duration effects observed in the present study is based on the idea that activation of motivational systems prompts approach and avoidance behavioral tendencies (1). Chen and Bargh (34) tested whether automatic stimulus evaluation results directly in behavioral predisposition towards a stimulus, such that positive evaluations would produce immediate approach tendencies, and negative evaluations would produce immediate avoidance tendencies. Subjects responded to attitude object stimuli either by pushing or by pulling a lever. They responded faster to negatively valenced stimuli when pushing the lever away ("avoid") than when pulling it toward them ("approach"), but responded faster to positive stimuli by pulling than by pushing the lever. The results of Chen and Bargh (34) suggest that the automatic classification of stimuli as either positive or negative appears to have direct behavioral consequences. Duckworth et al. (35) used positive and negative novel pictures on a paradigm of simple reaction time. The participants in the approach condition were instructed to pull a lever towards them when they detected the picture and responded faster to positive than to negative stimuli. Those in the avoidance condition responded by pushing the lever away from them. Responses were now faster to negative than to positive novel stimuli. They concluded that, as found for familiar stimuli, the automatic evaluation of novel stimuli has direct and immediate consequences for approach and avoidance behavioral tendencies. In a related study by Wentura et al. (36), subjects participated in a go/no-go lexical decision task in which they had to withdraw their finger from a pressed key ("avoid") or had to press a key ("approach") if a word was presented. Responses to negative words were relatively faster in the withdraw condition, whereas responses to positive words were relatively faster in the press condition.

The interpretation of our data in terms of approach and avoidance behavior linked to motivational systems predicts that unpleasant pictures should engage the subject in an avoidance-like behavior and positive pictures should engage the subject in an approach-like behavior. The slower reaction time for mutilation pictures is consistent with the former. However, we did not obtain any evidence for an approach-like behavior in the case of pleasant pictures since the reaction time for positive pictures was not faster than that for neutral pictures. In the present study, however, positive pictures consisted of photos of nude males presented to female subjects. Although rated as pleasant, it is possible that they also caused some sort of embarrassment or awkwardness to the subjects. This could potentially counterbalance the "pleasantness" of the pictures. The double nature of the affect associated with nude pictures when employed in laboratory experiments has been pointed out by others (37). The absence of any evidence of approach-like behavior in this study was also described in our previous work with male subjects (16). The data reported by Bradley et al. (10) suggest that men and women diverged in their reports of emotional expe- 
rience when viewing erotic pictures of the opposite sex, with a higher proportion of men reporting that they felt "sexy" and "excited", whereas women reported feeling "amused" and "embarrassed", and with less agreement amongst themselves. In the present study we found no evidence that erotic stimuli induce a different pattern of behavioral response between women and men. Bradley et al. (10) reported that when exposed to nude pictures of their same sex, both men and women rated them as neutral and low arousing. Interestingly, physiological measures, such as heart rate and startle reflex magnitude, showed that implicit emotional reactions were as strong as those for the opposite sex pictures. This may mean that explicit reports are more prone to be constrained by social influences. Then, differences in evaluative judgments of emotional pictures do not always predict their modulatory effect on behavior.

Beyond the comparisons between men and women, taking individual differences into account has shed light on the mechanisms underlying emotional reactions (see review by Kosslyn et al., Ref. 38). Measures of affective trait will be conducted in our future studies. Other issues for future investigations include increasing the number of trials after the picture's offset to check for the extent to which the modulation by unpleasant pictures is present, and employing functional neuroimaging techniques to unravel the neural circuits underlying the behavioral modulation reported here.

\section{References}

1. Lang PJ, Davis M \& Ohman A (2000). Fear and anxiety: animal models and human cognitive psychophysiology. Journal of Affective Disorders, 61: 137-159.

2. LeDoux J (1996). The Emotional Brain. Simon \& Schuster, New York, 384.

3. Lang PJ, Greenwald MK, Bradley MM \& Hamm AO (1993). Looking at pictures: affective, facial, visceral, and behavioral reactions. Psychophysiology, 30: 261-273.

4. Ohman A (2000). Fear and anxiety: evolutionary, cognitive, and clinical perspectives. In: Lewis $M$ \& Havilland-Jones $M$ (Editors), Handbook of Emotions. Guilford Press, New York, 573-593.

5. Ohman A, Esteves F \& Soares JJ (1995). Preparedness and preattentive associative learning: Electrodermal conditioning to masked stimuli. Journal of Psychophysiology, 9: 99-108.

6. Fischer $\mathrm{AH}$ \& Manstead ASR (2000). The relation between gender and emotion in different cultures. In: Fischer AH (Editor), Gender and Emotion: Social Psychology Perspectives. Cambridge University Press, New York, 71-94.

7. Brody LR \& Hall JA (1993). Gender and emotion. In: Lewis M \& Havilland JM (Editors), Handbook of Emotions. Guilford Press, New York, 447-460

8. Kring AM \& Gordon AH (1998). Sex differences in emotion: expression, experience, and physiology. Journal of Personality and Social Psychology, 74: 686-703.

9. Allen JG \& Haccoun DM (1976). Sex differences in emotionality: A multidimensional approach. Human Relations, 29: 711-722.

10. Bradley MM, Codispoti M, Sabatinelli D \& Lang PJ (2001). Emotion and motivation II: Sex differences in picture processing. Emotion, 1: 300-319.

11. Lang PJ, Bradley MM \& Cuthbert BN (1997). Motivated attention: Affect, activation, and action. In: Lang PJ, Simons RF \& Balaban MT (Editors), Attention and Orienting: Sensory and Motivational Processes. Lawrence Erlbaum Associates, Mahwah, NJ, USA, 97-135.
12. Hartikainen KM, Ogawa KH \& Knight RT (2000). Transient interference of right hemispheric function due to automatic emotional processing. Neuropsychologia, 38: 1576-1580.

13. Tipples J \& Sharma D (2000). Orienting to exogenous cues and attentional bias to affective pictures reflect separate processes. British Journal of Psychology, 91 (Part 1): 87-97.

14. Bradley MM, Codispoti M, Cuthbert BN \& Lang PJ (2001). Emotion and motivation I: Defensive and appetitive reactions in picture processing. Emotion, 1: 276-298.

15. Bradley MM, Sabatinelli D, Lang PJ, Fitzsimmons JR, King W \& Desai P (2003). Activation of the visual cortex in motivated attention. Behavioral Neuroscience, 117: 369-380.

16. Pereira MG, Volchan E, Machado-Pinheiro W, Oliveira L, Rodrigues JA, Nepomuceno FVP, Pessoa L \& Gawryszewski LG (2001). Unpleasant pictures induce a prolonged increase in manual reaction time. Society for Neuroscience 31st Annual Meeting, Abstract 645.10.

17. Oldfield RC (1971). The assessment and analysis of handedness: the Edinburgh Inventory. Neuropsychologia, 9: 97-113.

18. Lang PJ, Bradley MM \& Cuthbert B (1997). International Affective Picture System (IAPS): Instruction Manual and Affective Ratings. University of Florida, NIMH Center for the Study of Emotion and Attention, Gainesville, FL, USA.

19. Center for the Study of Emotion and Attention (1999). The International Affective Picture System: Digitized Photographs. University of Florida, Gainesville, FL, USA.

20. Bradley MM, Cuthbert BN \& Lang PJ (1996). Picture media and emotion: effects of a sustained affective context. Psychophysiology, 33: 662-670.

21. Lang PJ (1980). Behavioral treatment and bio-behavioral assessment: computer applications. In: Sidowsk JB, Johnson JH \& Williams TA (Editors), Technology in Mental Health Care Delivery Systems. Ablex, Norwood, NJ, USA, 119-137. 
22. Bradley MM \& Lang PJ (1999). Affective Norms for English Words (ANEW): Instruction Manual and Affective Ratings (Tech. Rep. No. C-1). University of Florida, The Center for Research in Psychophysiology, Gainesville, FL, USA.

23. Bradley MM \& Lang PJ (1999). International Affective Digitized Sounds (IAD): Instruction Manual and Affective Ratings (Tech. Rep. No. B-1). University of Florida, The Center for Research in Psychophysiology, Gainesville, FL, USA.

24. Gross JJ \& John OP (1998). Mapping the domain of expressivity: multimethod evidence for a hierarchical model. Journal of Personality and Social Psychology, 74: 170-191.

25. Duncan J, Ward R \& Shapiro K (1994). Direct measurement of attentional dwell time in human vision. Nature, 369: 313-315.

26. Muller MM, Teder-Salejarvi W \& Hillyard SA (1998). The time course of cortical facilitation during cued shifts of spatial attention. Nature Neuroscience, 1: 631-634.

27. Lang PJ, Bradley MM, Fitzsimmons JR, Cuthbert BN, Scott JD, Moulder B \& Nangia $V$ (1998). Emotional arousal and activation of the visual cortex: an fMRI analysis. Psychophysiology, 35: 199-210.

28. Mourao-Miranda J, Volchan E, Moll J, Oliveira-Souza R, Oliveira L, Bramati I, Gattass R \& Pessoa L (2003). Contributions of stimulus valence and arousal to visual activation while viewing emotionladen stimuli. Neuroimage (in press).

29. Codispoti M, Gerra G, Montebarocci O, Zaimovic A, Raggi MA \& Baldaroa B (2003). Emotional perception and neuroendocrine changes. Psychophysiology, 40: 863-868.

30. Marks IM (1987). Fears, Phobias and Rituals. Oxford University
Press, Oxford, New York.

31. Hebb DO (1946). On the nature of fear. Psychological Review, 53 : 250-275.

32. Stevens DA \& Gerzov-Thomas DA (1977). Fright reactions in rats to conspecific tissue. Physiology and Behavior, 18: 47-51.

33. Azevedo TM, Volchan E, Rodrigues EC, Pantoja ALH, Imbiriba LA, Oliveira JM, Lutterbach LG, Franca JG \& Vargas CD (2002). Cardiac and postural modulation by affective pictures in humans. Society for Neuroscience 32nd Annual Meeting, Abstract 381.5.

34. Chen M \& Bargh JA (1999). Consequences of automatic evaluation: Immediate behavioral predispositions to approach or avoid the stimulus. Personality and Social Psychology Bulletin, 25: 215-224.

35. Duckworth KL, Bargh JA, Garcia M \& Chaiken S (2002). The automatic evaluation of novel stimuli. Psychological Science, 13: 513519.

36. Wentura D, Rothermund K \& Bak P (2000). Automatic vigilance: the attention-grabbing power of approach- and avoidance-related social information. Journal of Personality and Social Psychology, 78: 10241037.

37. Kaviani H, Gray JA, Checkley SA, Kumari V \& Wilson GD (1999). Modulation of the acoustic startle reflex by emotionally-toned filmclips. International Journal of Psychophysiology, 32: 47-54.

38. Kosslyn SM, Cacioppo JT, Davidson RJ, Hugdahl K, Lovallo WR Spiegel D \& Rose R (2002). Bridging psychology and biology. The analysis of individuals in groups. American Psychology, 57: 341 351 